\title{
Pycnoporus cinnabarinus glyoxal oxidases display differential catalytic efficiencies on 5-hydroxymethylfurfural and its oxidized derivatives
}

\author{
Marianne Daou ${ }^{1}$, Bassem Yassine ${ }^{1}$, Saowanee Wikee ${ }^{1}$, Eric Record ${ }^{1}$, Françoise Duprat ${ }^{2}$, Emmanuel Bertrand $^{1}$ \\ and Craig B. Faulds ${ }^{1 *}$ (D)
}

\begin{abstract}
Background: 5-Hydroxymethylfurfural (HMF), a major residual component of a lignocellulosic bio-refinery process, can be transformed into fundamental building blocks for green chemistry via oxidation. While chemical methods are well established, interest is also being directed into the enzymatic oxidation of HMF into the bio-plastic precursor 2,5-furandicarboxylic acid (FDCA).

Results: We demonstrate that three glyoxal oxidases (PciGLOX) isoenzymes from the Basidiomycete fungus Pycnoporus cinnabarinus were able to oxidize HMF, with PciGLOX2 and PCiGLOX3 being the most efficient. The major reaction product obtained with the three isoenzymes was 5-hydroxymethyl-2-furancarboxylic (HMFCA), a precursor in polyesters and pharmaceuticals production, and very little subsequent conversion of this compound was observed. However, small concentrations of FDCA, a substitute for terephthalic acid in the production of polyesters, were also obtained. The oxidation of HMF was significantly boosted in the presence of catalase for PciGLOX2, leading to 70\% HMFCA yield. The highest conversion percentages were observed on 2,5-furandicarboxaldehyde (DFF), a minor product from the reaction of PCiGLOX on HMF. To bypass HMFCA accumulation and exploit the efficiency of PciGLOX in oxidizing DFF and 5-formyl-2-furan carboxylic acid (FFCA) towards FDCA production, HMF was oxidized in a cascade reaction with an aryl alcohol oxidase (UmaAAO). After $2 \mathrm{~h}$ of reaction, UmaAAO completely oxidized HMF to DFF and further to FFCA, with FDCA only being detected when PciGLOX3 was added to the reaction. The maximum yield of $16 \%$ FDCA was obtained $24 \mathrm{~h}$ after the addition of PCiGLOX3 in the presence of catalase.
\end{abstract}

Conclusions: At least two conversion pathways for HMF oxidation can be considered for PciGLOX; however, the highest selectivity was seen towards the production of the valuable polyester precursor HMFCA. The three isoenzymes showed differences in their catalytic efficiencies and substrate specificities when reacted with HMF derivatives.

Keywords: 5-Hydroxymethylfurfural, Bio-catalysis, Glyoxal oxidase, 2,5-Furancarboxylic acid, Furan derivatives

\footnotetext{
*Correspondence: craig.faulds@univ-amu.fr

${ }^{1}$ INRA, UMR1163 Biodiversité et Biotechnologie Fongiques (BBF), Aix

Marseille Université, 13009 Marseille, France

Full list of author information is available at the end of the article
} 


\section{Background}

With the growing concerns about the depleting supply of fossil fuel and the global problem of climate change, the demands for sustainable substitutes for petroleum-based products are increasing. Being one of the most abundant renewable natural materials on earth, plants have become a major candidate for this role, especially those species that yield low-cost residues from agro-industrial processing. Approximately $75 \%$ of annual production of agro-industrial residues is in the form of carbohydrates, making this material highly exploitable [1]. Efforts are being directed for the conversion of plant carbohydrates into valuable chemicals and fuels. Among the valuable platform chemicals that can be obtained from biomass carbohydrates are 5-hydroxymethylfurfural (HMF) and furfural [2], produced by triple dehydration of hexoses [3] and acid hydrolysis of pentosans, respectively [4].

HMF is particularly important due to its biodegradability and its versatility as a precursor for a wide selection of furan-based products, and has been recognized as top value-added molecule in biotechnology [5]. Important molecules derived from HMF include dimethylfuran, levulinic acid, 2,5-furandicarboxylic acid (FDCA), 2,5-diformylfuran (DFF), 3,5-dihydroxymethylfuran, 5-hydroxy-4-keto-pentenoic acid and 5-hydroxymethyl2-furancarboxylic acid (HMFCA) [6]. DFF is a stable derivative of HMF. This molecule is considered important for the synthesis of pharmaceutical compounds [7], antifungal products [8], electroconductors [9] and polymeric materials [10]. Another important product from the oxidation of the aldehyde group of HMF is HMFCA.
This is particularly important for the production of polyesters [11] and interleukin inhibitors [12], and was found to have in vivo antitumor activity against Sarcoma 180 cells [13]. Furan-based derivatives also include FDCA, which was considered among the 12 most promising sugar-based molecules for the production of bio-based material [14]. FDCA is particularly important because it can replace fossil-based terephthalic acid for the production of bio-based polyesters [15]. Chemically, HMF derivatives are produced using metals as catalysts under extreme conditions such as high temperature, high pressure and in the presence of toxic solvents. The development of bio-catalytic processes is therefore advantageous since enzymes work under mild conditions, which can reduce the energy required and the production cost.

Among the enzymes that were previously tested and used for the oxidation of HMF are three alcohol oxidases (EC 1.1.3.13) and one galactose oxidase (GAO; EC 1.1.3.9) that have been reported to oxidize HMF leading to the formation of DFF as the sole product following the reaction presented in Fig. 1 [16]. Synthesis of HMFCA by bio-catalysis remained limited due to the need of high reaction selectivity in order to oxidize the aldehyde group and leave the hydroxyl group intact [17]. Xanthine oxidase (EC 1.17.3.2) from Escherichia coli was used for the selective oxidation of HMF to HMFCA [16]. Oxidative conversion of HMF to FDCA was also performed following a two-steps reaction using fungal aryl-alcohol oxidase (AAO; EC 1.1.3.7) and an unspecific heme peroxygenase (EC 1.11.2.1) [18]. Full HMF conversion with high FDCA yields was also achieved using an FAD-dependent

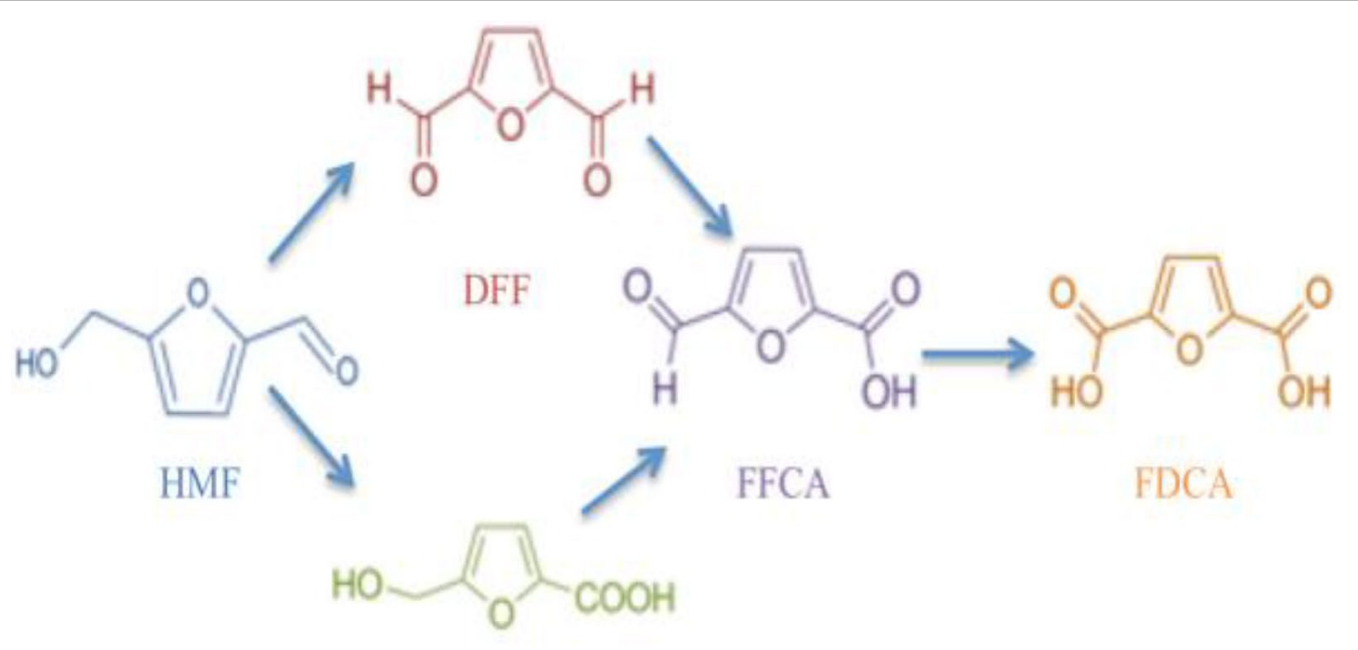

HMFCA

Fig. 1 The oxidation reaction pathways of HMF to FDCA (Carro et al. [18]) 
oxidase, named HMF oxidase (HMFO; EC 1.1.3.47) [19, 20].

Although HMF derivatives are highly important, limited examples describing the synthesis of these compounds via enzymatic reactions were previously described and the pursuit for new enzymes that can be involved in this process is still highly interesting. Promising candidates are enzymes with versatile substrate specificity able to perform the successive oxidation steps required in the process by recognizing HMF and its derivatives as substrates.

Glyoxal oxidases (GLOX; EC 1.2.3.15) are metalloenzymes containing one copper metal ion, and belong to a class of enzymes called radical copper oxidases [21]. These enzymes have been grouped within the AA5 family in the CAZymes (Carbohydrate Active Enzymes database; http://www.cazy.org/) classification system [22, 23]. GLOX catalyzes the oxidation of aldehydes to their corresponding carboxylic acids, generating simultaneously hydrogen peroxide $\left(\mathrm{H}_{2} \mathrm{O}_{2}\right)[24,25]$. This enzyme was first isolated in ligninolytic cultures of the white-rot Basidiomycete Phanerochaete chrysosporium under restricted nitrogen supply, suggesting a role in lignin modification and peroxidase $\mathrm{H}_{2} \mathrm{O}_{2}$-dependent action [26]. Subsequent sequencing and analysis of the $P$. chrysosporium genome has indicated the presence of only one gene encoding GLOX in this fungus [27]. The genome of another Polyporale fungus, Pycnoporus cinnabarinus [28], contains 3 glox genes. In vitro characterization of these GLOX revealed their ability to act on a broad range of substrates including toxic and inhibitory aldehydes [24, 25]. In addition, GLOX were able to recognize and oxidize the alcohol group of glycerol extending further the specificity range of these enzymes [25, 29]. Although the utilization of GLOX for biotechnological applications had not previously been elaborated upon, the reactions catalyzed by this enzyme made it a promising candidate, especially for the oxidation of HMF and its derivatives.

In this work, the ability of two previously produced and characterized GLOX from P. cinnabarinus strain BRFM 137 (PciGLOX1 and PciGLOX2) [25] and a third isoform from this fungus (PciGLOX3) to oxidize HMF and its derivatives was investigated.

\section{Results}

\section{PciGLOX3 characterization}

PciGLOX3 shared $84 \%$ and $89 \%$ protein sequence identity with PciGLOX1 and PciGLOX2, respectively, and the amino acids at the active site were highly conserved (Fig. 2). PciGLOX3 was heterologously produced in Aspergillus niger and purified. The enzyme showed a generally lower activity on the tested substrates compared to the other two PciGLOX enzymes, however, the specificity range for all three isoenzymes was similar except in the case of glycerol, which was only oxidized by PciGLOX2 and PciGLOX3 (Table 1). One major difference observed was that highest activity detected on formaldehyde for PciGLOX3 while the two other enzymes were most active on glyoxylic acid. Differences in the kinetic constants were also observed for PciGLOX3 that showed the highest specificity and catalytic efficiency on glycerol compared to the other enzymes (Table 2). In addition, PciGLOX3 was less efficient in oxidizing glyoxylic acid compared to the two other GLOX.

\section{Enzyme stability under the conditions of reaction}

The standard reaction conditions for the oxidation of HMF and its derivatives were chosen based on the stability and performance of the enzymes under these conditions. The optimal pH was 6 and the enzymes were active in dimethylsuccinate and tartrate buffers [25]. The reactions were performed in tartrate buffer, as dimethylsuccinate could not be resolved from the substrates and expected products of the enzymatic reaction in the HPLC analysis. The stability of PciGLOX enzymes under these conditions and over a prolonged period of time were assessed. PciGLOX2 was the least stable of the three isoenzymes and lost around 90\% of its activity after $2 \mathrm{~h}$ of incubation (Fig. 3a). On the other hand, PciGLOX1 and PciGLOX3 retained $70 \%$ and $40 \%$ of their activities after $48 \mathrm{~h}$ of incubation, respectively. The stability of the three enzymes was also assessed in the presence of $3 \mathrm{mM}$ HMF. In the presence of this substrate, no activity was detected for PciGLOX2 after $2 \mathrm{~h}$ of incubation (Fig. 3b). On the other hand, the activities of PciGLOX1 and PciGLOX3 were relatively stable with PciGLOX3 showing increased residual activity after $48 \mathrm{~h}$. The stability of the three PciGLOX enzymes was further investigated in the presence of $3 \mathrm{mM}$ HMFCA, which is the major theoretically expected product of the reaction on HMF. In the presence of this molecule, the significant loss in activity after $24 \mathrm{~h}$ of incubation was comparable between the three isoforms (Fig. 3c). Horseradish peroxidase (HRP) was highly stable under the tested conditions (Additional file 1).

\section{Stability towards $\mathrm{H}_{2} \mathrm{O}_{2}$}

The stability of the three PciGLOX isoenzymes was investigated in the presence of varying concentrations of $\mathrm{H}_{2} \mathrm{O}_{2}$. PciGLOX1 was the most stable enzyme in the presence of this reaction product, retaining $60 \%$ of its activity when incubated with $10 \mathrm{mM} \mathrm{H}_{2} \mathrm{O}_{2}$ for $24 \mathrm{~h}$ (Fig. 4). Although more stable than PciGLOX3, PciGLOX2 significantly lost activity with increasing concentrations of $\mathrm{H}_{2} \mathrm{O}_{2}$ and lost more than $95 \%$ of its activity after incubation in the presence of $8 \mathrm{mM} \mathrm{H}_{2} \mathrm{O}_{2}$. PciGLOX3 on the 


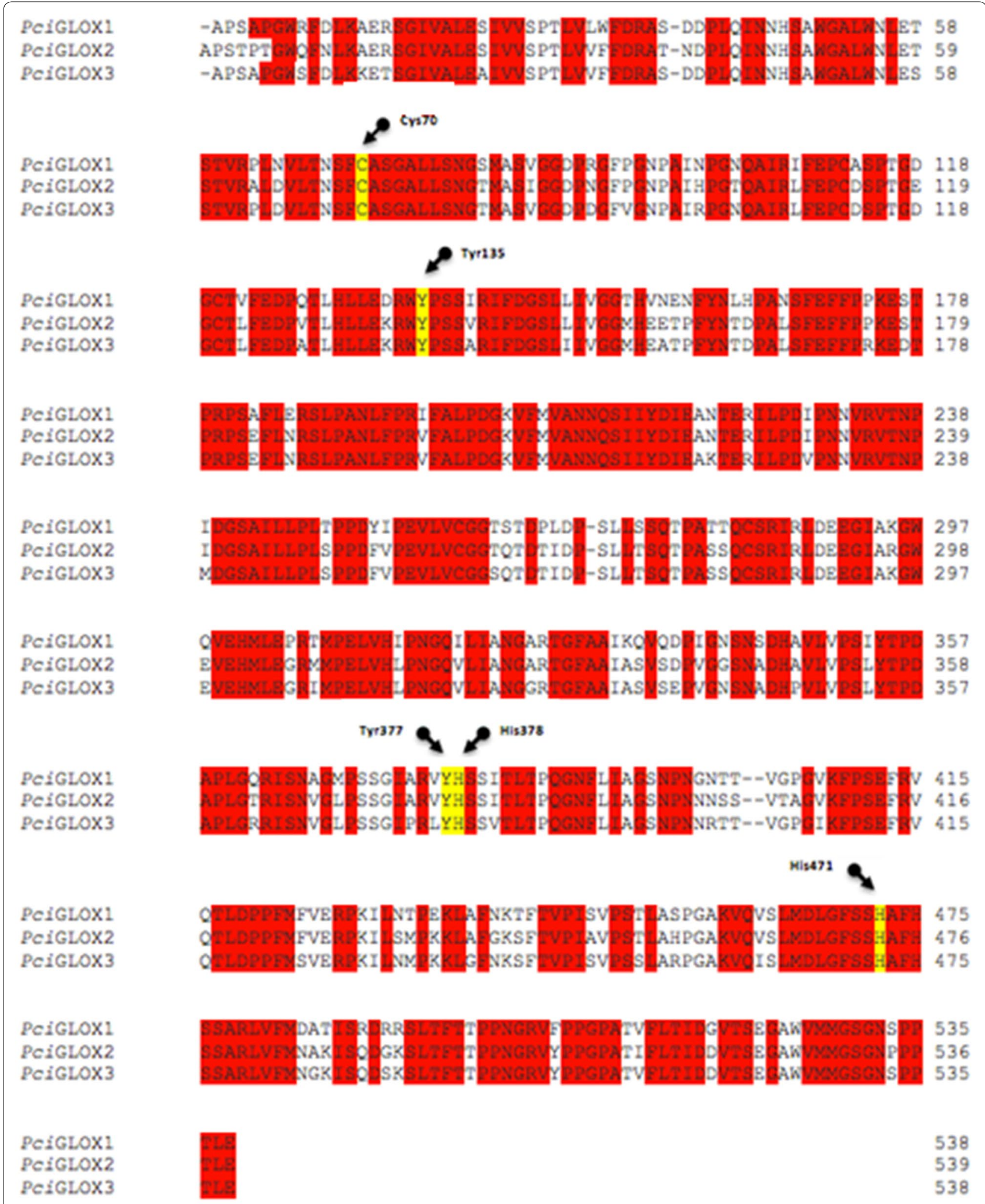

Fig. 2 Custal W alignment of P. cinnarbarinus GLOX proteins. Identical residues are highlighted in red. Arrows indicate residues essential for catalysis 
Table 1 Substrate specificity of PciGLOX3 compared to previously characterized PciGLOX1 and PciGLOX2 (Daou et al. [25])

\begin{tabular}{llll}
\hline Substrate (10 mM) & \multicolumn{3}{l}{ Activity (nkat/mg) } \\
\cline { 2 - 4 } & PciGLOX1 & PciGLOX2 & PciGLOX3 \\
\hline Methyl glyoxal & 814 & 291 & 90 \\
Glyoxal & 392 & 163 & 68 \\
Glyoxylic acid & 1562 & 384 & 59 \\
3-Phenylpropionaldehyde & 10 & 135 & 51 \\
Formaldehyde & 50 & 202 & 133 \\
DL-glyceraldehyde & 11 & 66 & 26 \\
Dihydroxyacetone & 108 & 157 & 64 \\
Glycerol & 2 & 61 & 88 \\
2,4-Dimethoxybenzaldehyde & ND & 2 & ND \\
Veratraldehyde & ND & ND & ND \\
4-Hydroxybenzaldehyde & ND & ND & ND \\
Phenyl glyoxilic acid & ND & ND & ND \\
Formic acid & ND & ND & ND \\
D-glucose & ND & ND & ND \\
D-galactose & ND & ND & ND \\
D-xylose & ND & ND & ND \\
Methanol & ND & ND & ND \\
\hline ND, actity notdeteted & &
\end{tabular}

ND, activity not detected under these assay conditions

other hand lost $60 \%$ of its activity with only $2 \mathrm{mM} \mathrm{H}_{2} \mathrm{O}_{2}$ and was completely inactive with $10 \mathrm{mM} \mathrm{H}_{2} \mathrm{O}_{2}$ after $24 \mathrm{~h}$ of incubation.

\section{Oxidation of HMF and its derivatives by PciGLOX}

The three PciGLOX isoenzymes were found to be active on HMF and this became evident by the decrease in HMF concentration and the appearance of the oxidation products over time (Fig. 5, Additional file 2). Although the catalytic efficiencies of the three enzymes were comparable on HMF (Table 3), the conversion percentage of this substrate varied between the PciGLOX enzymes (14\% for PciGLOX1, 34\% for PciGLOX2 and 28\% for PciGLOX3).
In addition, the three isoenzymes noticeably differed in their products' patterns.

The major product of the reactions of the PciGLOX isoenzymes on HMF was HMFCA with PciGLOX2 and PciGLOX3 producing the highest yields (39\% and $41 \%$, respectively; Fig. 5b, c). By adding catalase to the reaction of PciGLOX2, the amount of produced HMFCA was considerably increased to $76 \%$ (Fig. $5 \mathrm{~b}$ right). This increase was coupled to a significant boost in HMF conversion $(\mathrm{p}=0.062)$.

Interestingly, the addition of catalase seemed to shift the reaction more towards the production of HMFCA and decreased the amount of 5-formyl-2-furan carboxylic acid (FFCA) produced from 5 to $0.7 \%$. A weak activity-enhancing effect in the presence of catalase was also observed with PciGLOX3 but not with PciGLOX1.

Interestingly, small amounts of DFF, the alternative oxidation product of HMF, were also detected. The concentration of detected DFF slightly increased over time in the reaction with PciGLOX1 (0.017 $\mathrm{mM}$ at $24 \mathrm{~h})$. In the cases of PciGLOX2 and PciGLOX3, smaller DFF concentrations were detected early in the reaction. The substrate specificity and catalytic efficiencies of PciGLOX2 and PciGLOX3 on DFF as a substrate $(K \mathrm{~m}=0.2 \mathrm{mM}$; $K$ cat $/ K \mathrm{~m}=23,403 \quad \mathrm{~s}^{-1} \quad \mathrm{M}^{-1}$ and $K \mathrm{~m}=0.2 \quad \mathrm{mM}$; Kcat $/ K \mathrm{~m}=7267 \mathrm{~s}^{-1} \mathrm{M}^{-1}$, respectively) were significantly better than that of PciGLOX1 $(K \mathrm{~m}=4.3 \mathrm{mM}$; $K \mathrm{cat} / \mathrm{Km}=124.3 \mathrm{~s}^{-1} \mathrm{M}^{-1}$ ). This was further supported in the results obtained when DFF was used as the initial substrate and $80 \%$ to $84 \%$ converted by PciGLOX 2 and PciGLOX3, respectively (Fig. 6a).

The three PciGLOX were also reacted with HMFCA as the initial substrate. Although this compound was produced as the major product in HMF oxidation, the three PciGLOX showed very weak activity towards HMFCA, with PciGLOX3 having the best conversion rate $(2 \%$; Fig. 6b). The extent of HMFCA to FFCA conversion by PciGLOX was not sufficient to calculate catalytic constants. In addition, higher concentrations of FFCA and FDCA were obtained when the enzymes were reacted

Table 2 Kinetic constants of PciGLOX3 on Methylglyoxal, glyoxal, glyoxylic acid and glycerol compared to PciGLOX1 and PCiGLOX2 (Daou et al. [25])

\begin{tabular}{|c|c|c|c|c|c|c|}
\hline \multirow[t]{2}{*}{ Substrate } & \multicolumn{2}{|l|}{ PciGLOX1 } & \multicolumn{2}{|l|}{ PciGLOX2 } & \multicolumn{2}{|l|}{ PciGLOX3 } \\
\hline & $K_{\mathrm{m}}(\mathrm{mM})$ & $K_{\mathrm{cat}} / K_{\mathrm{m}}\left(\mathrm{s}^{-1} \mathrm{mM}\right)$ & $K_{\mathrm{m}}(\mathrm{mM})$ & $K_{\mathrm{cat}} / K_{\mathrm{m}}\left(\mathrm{s}^{-1} \mathrm{mM}\right)$ & $K_{\mathrm{m}}(\mathrm{mM})$ & $\begin{array}{l}K_{\text {cat }} / K_{\mathrm{m}} \\
\left(\mathrm{s}^{-1} \mathrm{mM}\right)\end{array}$ \\
\hline Methylglyoxal & 1.3 & 58.4 & 0.2 & 7 & 0.1 & 75.8 \\
\hline Glyoxal & 13.1 & 6.3 & 2.2 & 0.6 & 0.7 & 11.2 \\
\hline Glyoxylic acid & 0.08 & 2136.3 & 0.1 & 17 & 0.5 & 15.3 \\
\hline Glycerol & 660.5 & 0.04 & 9.4 & 0.06 & 5.5 & 1.4 \\
\hline
\end{tabular}



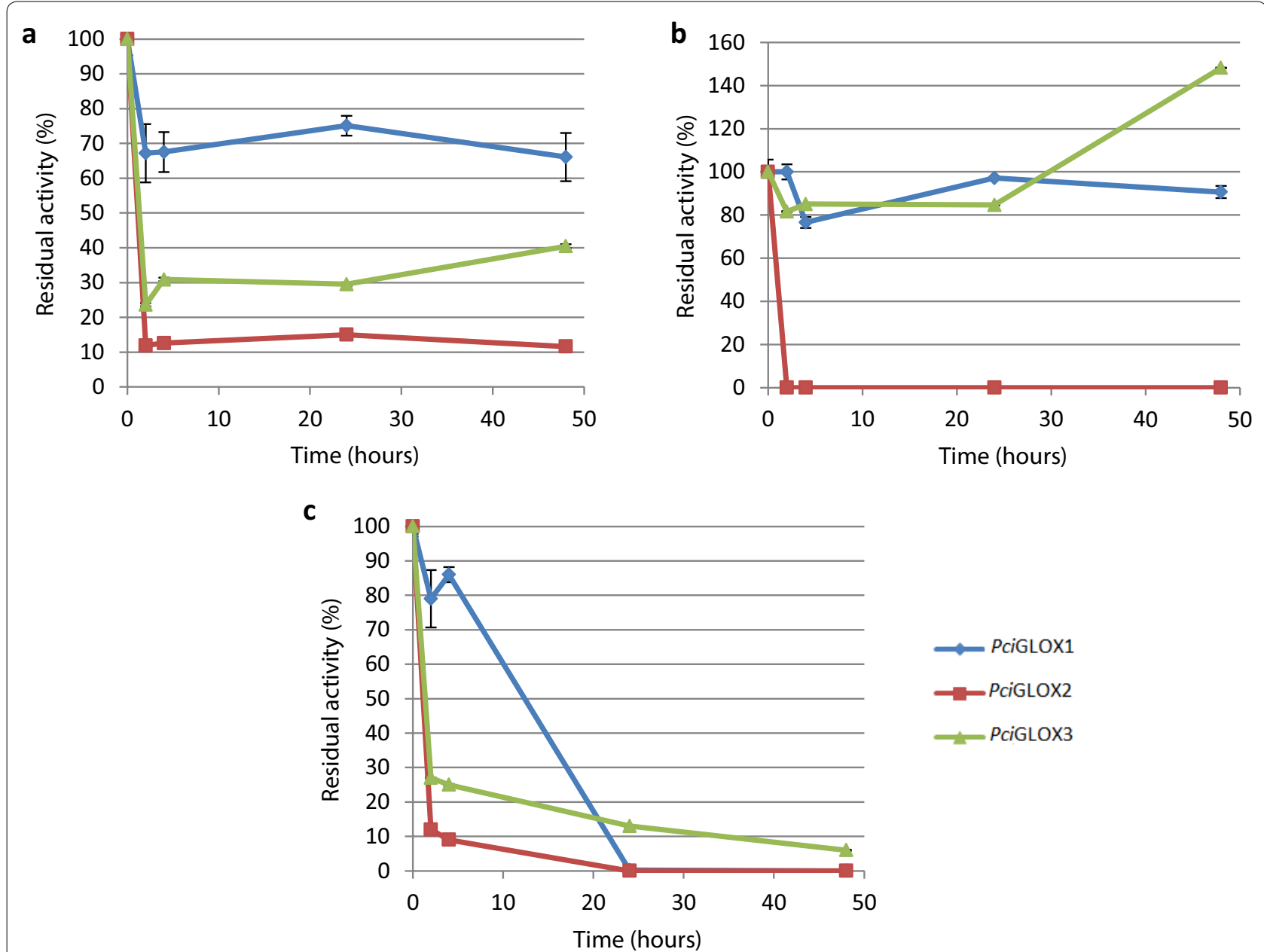

Fig. 3 Residual activity of the three PciGLOX after incubation at $30^{\circ} \mathrm{C}$ and $800 \mathrm{rpm}$ shaking in $50 \mathrm{mM}$ tartrate buffer pH6 in the absence (a) and presence (b) of $3 \mathrm{mM} \mathrm{HMF}$, and in the presence of $3 \mathrm{mM} \mathrm{HMFCA}(\mathbf{c})$. The residual activity was calculated as a percentage of the activity before incubation. Bars represent standard deviation

with DFF and FFCA as substrates, respectively (Fig. 6a, c).

\section{GLOX and AAO cascade reactions}

A cascade reaction where the aryl alcohol oxidase from Ustilago maydis (UmaAAO) was used to oxidize HMF followed by the addition of PciGLOX was tested. UmaAAo alone was found to efficiently oxidize HMF leading to the formation to DFF as the major product after $2 \mathrm{~h}$ of reaction. DFF was further oxidized by UmaAAO forming FFCA after $24 \mathrm{~h}$ of reaction (Fig. 7; Additional file 2b). PciGLOX3 was used in this experiment since this enzyme showed the highest conversion percentage on DFF (84\% after $24 \mathrm{~h})$ and the highest FDCA yields (14\% after $24 \mathrm{~h}$ on FFCA). Two conditions were tested: (1) PciGLOX3 was added after $2 \mathrm{~h}$ of UmaAAO reaction on HMF, and (2) PciGLOX3 was added after $24 \mathrm{~h}$ of UmaAAO reaction on $\mathrm{HMF}$.
Under condition (1) HMF was completely oxidized by UmaAAO and the major product before the addition of PciGLOX3 was DFF whereas in condition (2) FFCA was the predominant product.

After $4 \mathrm{~h}$ of adding PciGLOX3, FFCA was the major product $(2.6 \mathrm{mM})$ in the reaction and a little amount of DFF (0.5 mM) was detected (Table 4). Twenty hours later, DFF was almost completely consumed and the concentration of FDCA increased $(0.03 \mathrm{mM})$. In the presence of catalase, DFF was completely oxidized after $4 \mathrm{~h}$ of reaction and the concentration of FDCA obtained was 6 folds higher after $24 \mathrm{~h}$ (Table 4). The yield of FDCA was further increased in condition (2) to reach $14 \%$ and $16 \%$ after $24 \mathrm{~h}$ in the absence and presence of catalase, respectively (Table 4). The addition of PciGLOX3 to UmaAAO reaction on $\mathrm{HMF}$ was found to significantly increased the yields of FDCA $(p=0.026)$. The obtained yields in both tested conditions were comparable to the ones obtained 

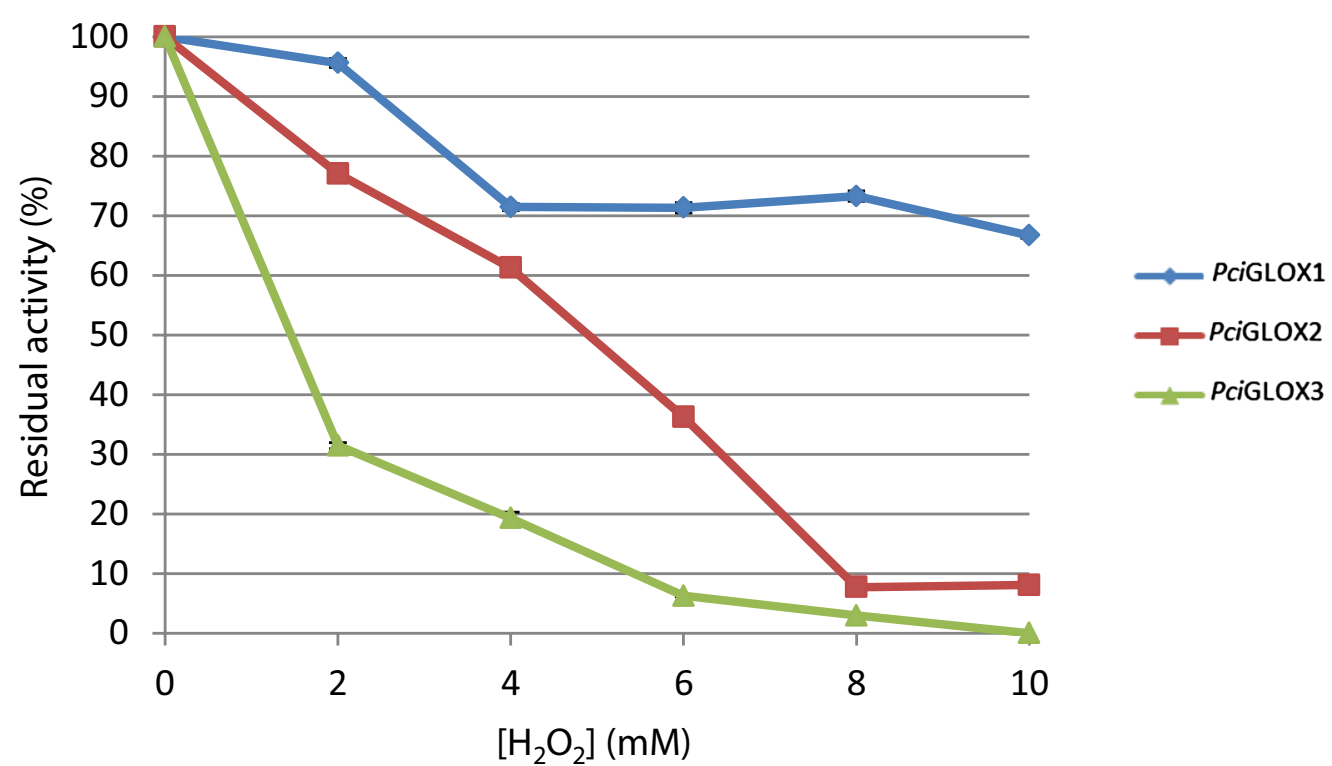

Fig. 4 Stability of the three PciGLOX in increasing concentrations of hydrogen peroxide after an incubation period of $24 \mathrm{~h}$. Bars represent standard deviation

when PciGLOX3 was reacted with DFF and FFCA as the initial substrates (Fig. 6).

\section{Discussion}

As mentioned in the introduction, HMF, a residue of the $2 \mathrm{G}$ lignocellulosic biorefinery, is of particular industrial importance due to its biodegradability and its versatility as a precursor for a wide selection of furan-based products, and as such has been recognized as a top value-added molecule in biotechnology. Currently, large chemical plants are being constructed to produce HMF, but a number of biological conversions have been identified in recent years, including the use of glyoxal oxidases as described in this paper. Although the three GLOX from $P$. cinnabarinus have a high protein sequence similarity and a conserved copper center, significant catalytic differences were observed and it was therefore interesting to compare the activity of all three enzymes on the conversion of HMF and its derivatives. The observed catalytic differences, in addition to the fact that PciGLOX3 has not yet been found to be secreted during fungal growth on different substrates [28], suggests different physiological roles of these enzymes during fungal growth.

While enzymatic assays with PciGLOX were performed at $30{ }^{\circ} \mathrm{C}$, the temperature at which fungi usually grows and secretes these enzymes in vitro, the $\mathrm{pH}$ and buffer system were also previously found to be critical factors for activity [25]. PciGLOX1 and PciGLOX3 were very stable under the reaction conditions used, while PciGLOX2 lost significantly activity over time, especially in the presence of its substrate, HMF. The stability of AAO from $P$. eryngii, which can also catalyze the oxidation of HMF to DFF, was previously determined in the presence of $3 \mathrm{mM}$ HMF, and the enzyme was found to lose $30 \%$ of its activity after $24 \mathrm{~h} \mathrm{[18].} \mathrm{Similarly} \mathrm{to} \mathrm{HMF,} \mathrm{the} \mathrm{major} \mathrm{reaction}$ product HMFCA seems to alter considerably the catalytic properties of the PciGLOX enzymes. It is difficult to determine if the observed changes in residual activity when HMF or HMFCA where added are due to changes in stability, or to either competitive or noncompetitive inhibition.

When incubated with different concentrations of $\mathrm{H}_{2} \mathrm{O}_{2}$ over time, the three isoenzymes again showed differences in stability. The inhibition of GLOX from Phanerochaete chrysosporium (PchGLOX) by exogenous $\mathrm{H}_{2} \mathrm{O}_{2}$ has previously been reported [30]. However, the three PciGLOX isoenzymes were found to be more stable than PchGLOX, which retained only $25 \%$ of its initial activity in the presence of $2.1 \mathrm{mM}$ exogenous $\mathrm{H}_{2} \mathrm{O}_{2}$ in the reaction mixture [30]. Furthermore, the detection of the reaction product of PchGLOX on glycerol was only possible when the activity was extended by adding catalase [29], which is not the case for PciGLOX [25]. $\mathrm{H}_{2} \mathrm{O}_{2}$ can oxidize proteins and alter the functional groups of certain amino acids leading to cleavage of the polypeptide chain and protein aggregation [31]. Therefore, one could postulate that the differences in stability observed between the three PciGLOX in the presence of $\mathrm{H}_{2} \mathrm{O}_{2}$ could be explained by structural variations between the three isoenzymes. 

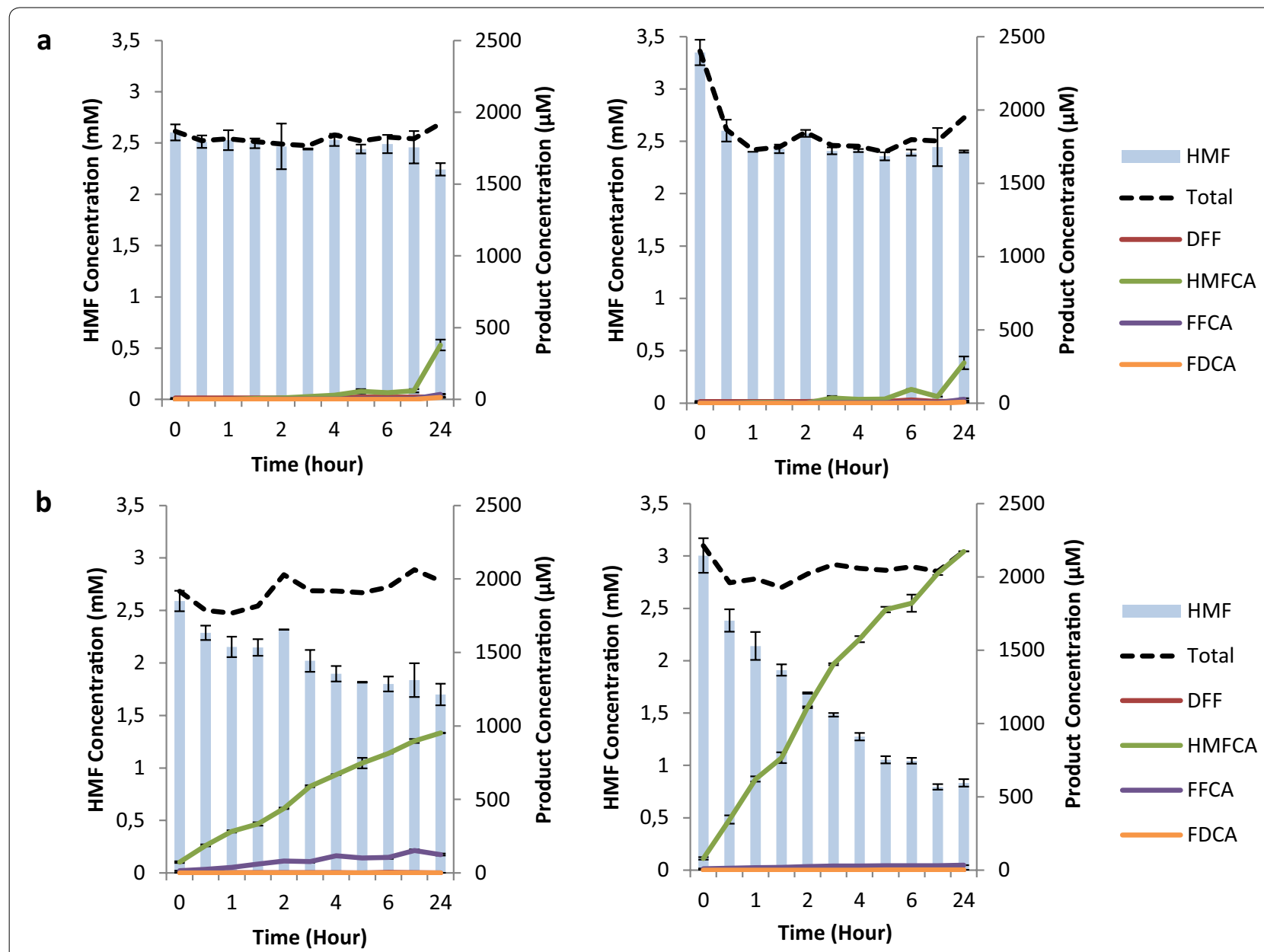

C
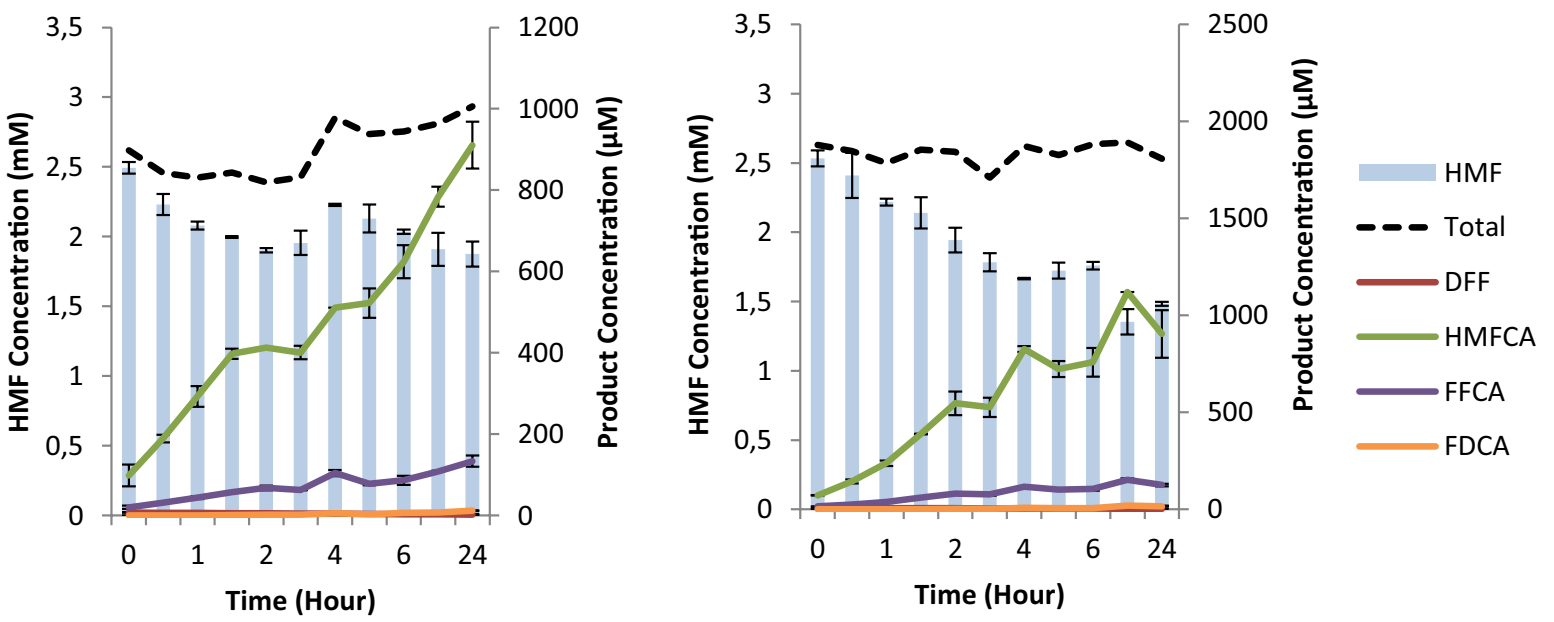

Fig. 5 HMF oxidation reaction follow-up over time in the absence (left) and presence (right) of catalase by a PCiGLOX1, b PCiGLOX2 and c PciGLOX3. Bars represent standard deviation

Significant differences in the kinetic parameters and products' yields for the oxidation of HMF were observed between the three enzymes, with the highest catalytic efficiency on HMF obtained with PciGLOX3
( $K \mathrm{cat} / \mathrm{Km}=118.35 \mathrm{~s}^{-1} \mathrm{M}^{-1}$ ). The oxidation of HMF using a phylogenetically different GLOX from Myceliophthora thermophila M77 (MtGLOX) has been recently published [32]. Similarly to PciGLOX described in this 
Table 3 Kinetic parameters for the oxidation of HMF, DFF, and FFCA by the three PciGLOX isoenzymes. Standard deviations are presented as plus-minus values

\begin{tabular}{lrrr}
\hline Substrate & \multicolumn{1}{c}{ PciGLOX1 } & \multicolumn{1}{l}{ PciGLOX2 } & \multicolumn{1}{c}{ PciGLOX3 } \\
\hline HMF & & & \\
$K_{\mathrm{m}}(\mathrm{mM})$ & $15.66 \pm 2.35$ & $5.87 \pm 2.04$ & $6.35 \pm 1.32$ \\
$K_{\text {cat }}\left(\mathrm{s}^{-1}\right)$ & $1.59 \pm 0.12$ & $0.56 \pm 0.09$ & $0.75 \pm 0.07$ \\
$K_{\text {cat }} / K_{\mathrm{m}}\left(\mathrm{s}^{-1} \mathrm{M}^{-1}\right)$ & $101.66 \pm 0.01$ & $96.04 \pm 0.01$ & $118.35 \pm 0.01$ \\
$D F F$ & & & \\
$K_{\mathrm{m}}(\mathrm{mM})$ & $4.38 \pm 0.1$ & $0.21 \pm 0.04$ & $0.18 \pm 0.05$ \\
$K_{\text {cat }}\left(\mathrm{s}^{-1}\right)$ & $0.54 \pm 0.24$ & $4.80 \pm 0.24$ & $1.28 \pm 0.09$ \\
$K_{\text {cat }} / K_{\mathrm{m}}\left(\mathrm{s}^{-1} \mathrm{M}^{-1}\right)$ & $124.39 \pm 0.01$ & $23,403.66 \pm 0.01$ & $7267.72 \pm 0.01$ \\
$F F C A$ & & & \\
$K_{\mathrm{m}}(\mathrm{mM})$ & $0.85 \pm 0.14$ & $1.40 \pm 0.39$ & $0.61 \pm 0.58$ \\
$K_{\text {cat }}\left(\mathrm{S}^{-1}\right)$ & $0.03 \pm 0.01$ & $2.02 \pm 0.03$ & $0.04 \pm 0.01$ \\
$K_{\text {cat }} / K_{\mathrm{m}}\left(\mathrm{s}^{-1} \mathrm{M}^{-1}\right)$ & $38.55 \pm 0.01$ & $1435.45 \pm 0.01$ & $72.03 \pm 0.01$ \\
\hline
\end{tabular}

paper, low conversion levels were observed with HMF. However $M t$ GLOX showed a higher catalytic efficiency and specificity towards HMF $\left(K\right.$ cat $/ K \mathrm{~m}=787 \mathrm{~s}^{-1} \mathrm{M}^{-1}$,
$K \mathrm{~m}=0.02 \mathrm{M}^{-1}$ ) compared to PciGLOX. Interestingly $M t G L O X$ oxidized the alcohol group of HMF leading to the formation of DFF.

Higher specificity and two-fold higher catalytic efficiency of AAO from $P$. eryngii were reported on HMF (Kcat $/ K \mathrm{~m}=210 \mathrm{~s}^{-1} \mathrm{M}^{-1}$ ) compared to that recorded in this study on PciGLOX [18]. In a more recent study using AAO for the oxidation of HMF, Karich and coworkers reported varying catalytic constants for the homologously produced AAO from $P$. eryngii on HMF with catalytic efficiency comparable to that obtained for PciGLOX [33]. However, P. eryngii AAO was less specific on HMF. Another enzyme used for the oxidation of HMF is the FAD-dependent oxidase, HMFO, which was more specific on HMF compared to PciGLOX and has a significantly higher catalytic efficiency $\left(K \mathrm{cat} / K \mathrm{~m}=7000 \mathrm{~s}^{-1} \mathrm{M}^{-1}\right.$ ) [19]. A 95\% conversion yield of HMF to FDCA was achieved using HMFO, however the concentration used was 60 times higher than the one used for PciGLOX in this work which only requires oxygen as an electron acceptor.

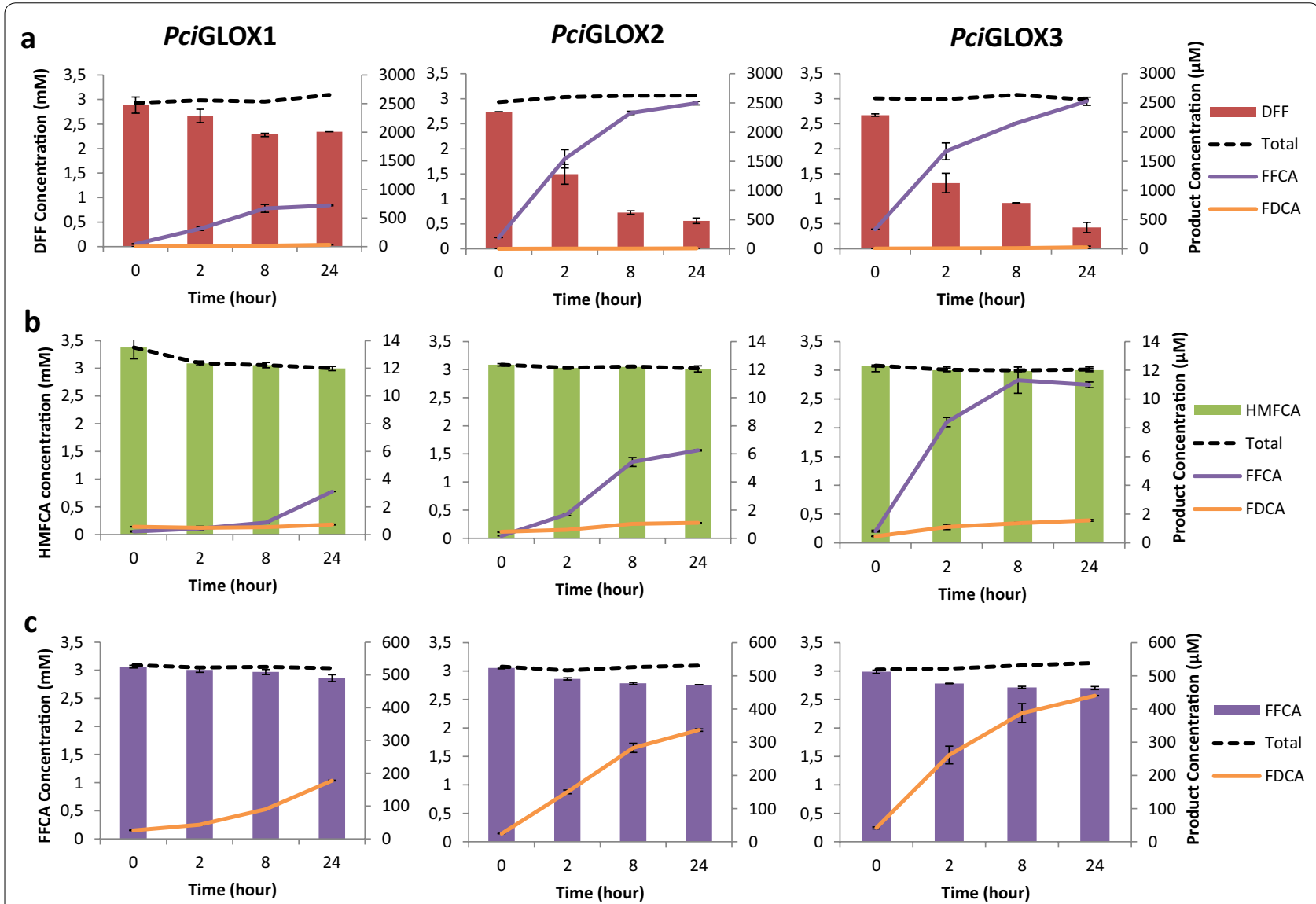

Fig. 6 Follow-up of the reactions of PCiGLOX1, PciGLOX2 and PCIGLOX3 on a DFF, b HMFCA and c FFCA as initial substrates. Bars represent standard deviation 
a

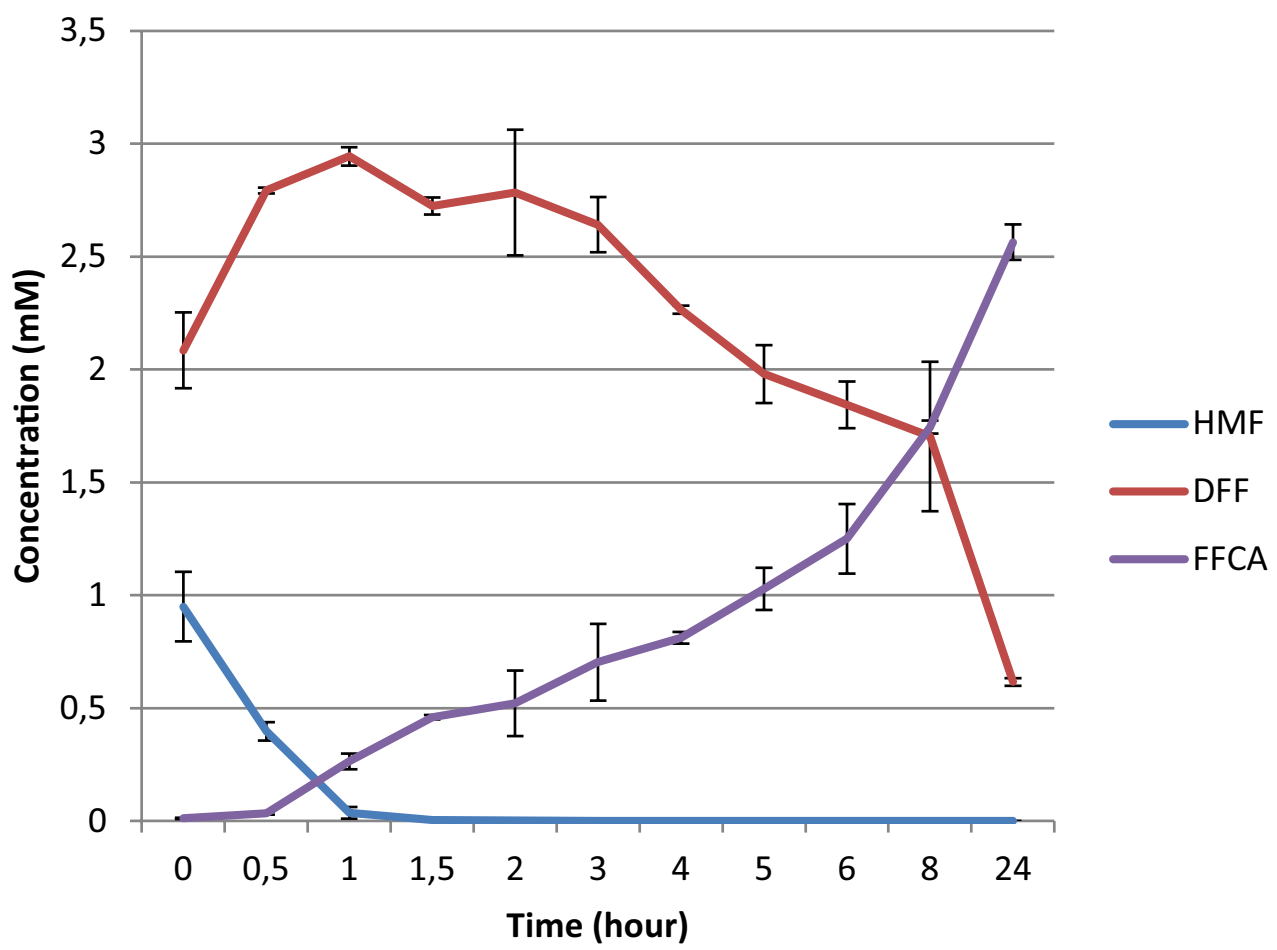

b

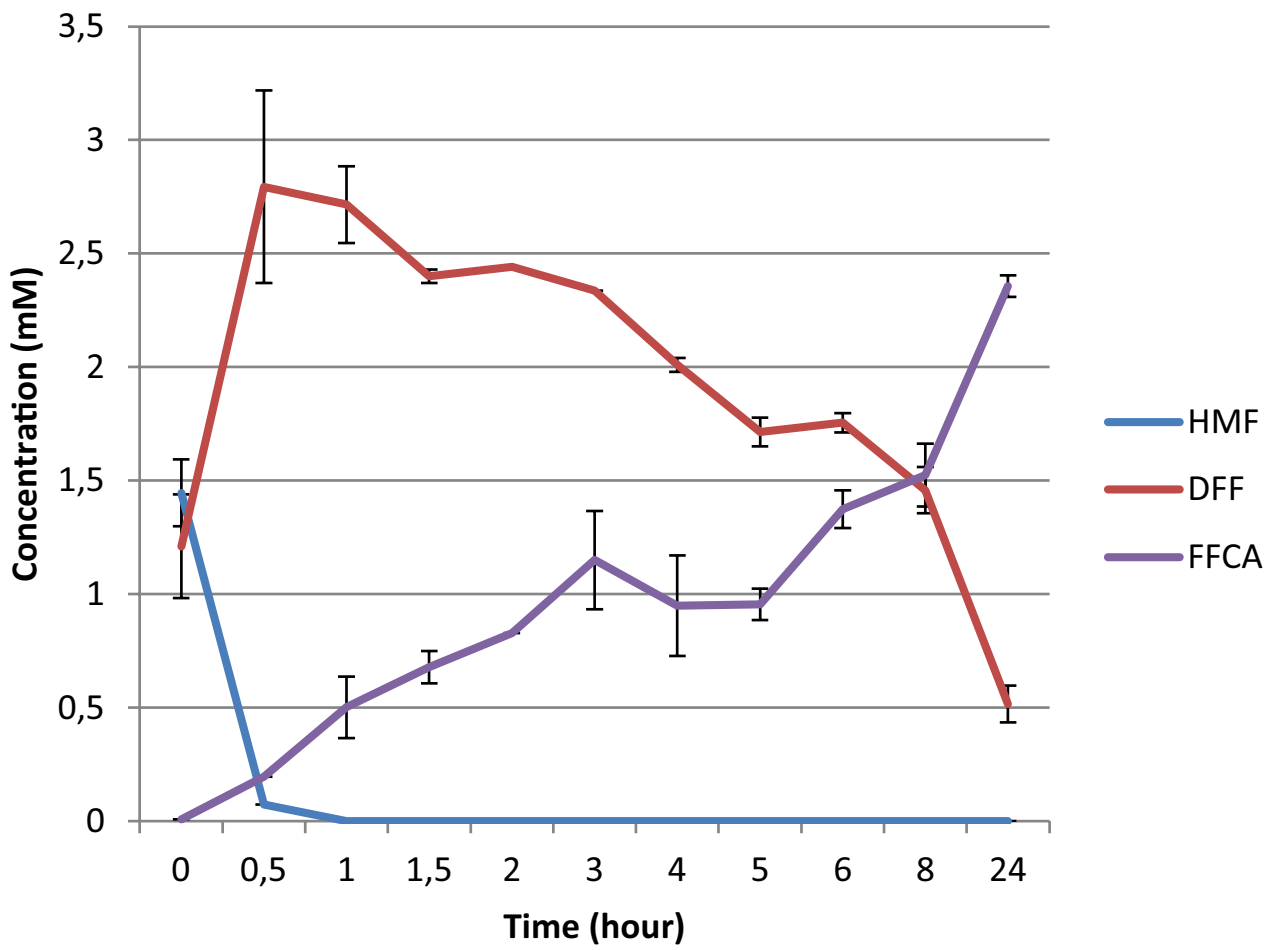

Fig. 7 Oxidation of HMF overtime by UmaAAO in the presence (a) and absence (b) of catalase. Bars represent standard deviation 
Table 4 Percentage content of HMF, DFF, FFCA and FDCA in the cascade reactions of UmaAAO and PciGLOX3 following condition (1) that consisted of reacting UmaAAO with HMF for $2 \mathrm{~h}$ before adding PciGLOX3 and condition (2) in which PciGLOX3 was added after $24 \mathrm{~h}$ of the reaction of UmaAAO with HMF

\begin{tabular}{|c|c|c|c|c|c|c|c|c|}
\hline & \multicolumn{4}{|c|}{ Condition (1) } & \multicolumn{4}{|c|}{ Condition (2) } \\
\hline & \multicolumn{2}{|l|}{ After $4 \mathrm{~h}$} & \multicolumn{2}{|l|}{ After $24 \mathrm{~h}$} & \multicolumn{2}{|l|}{ After $4 \mathrm{~h}$} & \multicolumn{2}{|l|}{ After $24 \mathrm{~h}$} \\
\hline & NC & $\mathrm{C}$ & NC & C & NC & C & NC & C \\
\hline HMF & ND & $N D^{a}$ & ND & ND & ND & ND & ND & ND \\
\hline DFF & $17 \% \pm 3.3$ & ND & $1 \% \pm 0.3$ & ND & ND & ND & ND & ND \\
\hline FFCA & $83 \% \pm 1.2$ & $96 \% \pm 0.1$ & $98 \% \pm 0.7$ & $94 \% \pm 0.1$ & $90 \% \pm 6.2$ & $87 \% \pm 5.3$ & $86 \% \pm 0.4$ & $84 \% \pm 1$ \\
\hline FDCA & ND & $4 \% \pm 0.8$ & $1 \% \pm 0.03$ & $6 \% \pm 0.03$ & $10 \% \pm 0.2$ & $13 \% \pm 0.6$ & $14 \% \pm 0.1$ & $16 \% \pm 1.2$ \\
\hline
\end{tabular}

Reactions were performed in the presence (C) and absence of catalase (NC) for both conditions. PciGLOX3 was reacted for 4 or $24 \mathrm{~h}$ before analyzing the reaction products. Standard deviations are presented as plus-minus values

a ND, values below $1 \%$

The major product of the PciGLOX reaction on HMF was HMFCA. This result was expected since GLOX recognizes the aldehyde group of its substrate [25], HMF in this case (Fig. 1). The need for this specificity has limited the number of described bio-catalytic pathways for the production of HMFCA. A previously described enzyme for this purpose is the bacterial xanthine oxidase (XO), which recognizes the formyl group of HMF [16]. Using $2.2 \mu \mathrm{M}$ of this enzyme, HMFCA was obtained with a yield of $94 \%$ after $7 \mathrm{~h}$ of reaction on $26 \mathrm{mM}$ HMF. The amount of PciGLOX used in this work was comparable to XO, but the yield of HMFCA obtained with PciGLOX2 after $24 \mathrm{~h}$ of reaction was significantly lower. However, a two folds increase in HMFCA yields was observed when catalase was added to PciGLOX2 reaction. This was in agreement with the results showing that PciGLOX2 was very sensitive to accumulating $\mathrm{H}_{2} \mathrm{O}_{2}$ concentrations. Catalase converts $\mathrm{H}_{2} \mathrm{O}_{2}$ to $\mathrm{O}_{2}$, protecting the enzymes from oxidative damage and supplying $\mathrm{O}_{2}$. This enzyme was previously used to eliminate the accumulating $\mathrm{H}_{2} \mathrm{O}_{2}$ from the action of alcohol oxidases on HMF [16]. In addition, catalase was found to boost HMF conversion in the coupled reaction of GAO and HRP, which is similar to the effect observed in this work [16].

In addition to HMFCA, small amounts of DFF were detected at early stages of the reaction especially with PciGLOX1. This result shows that PciGLOX are, to a smaller extent, able to act on the alcohol group of HMF. This is the second example of alcohol oxidation by these enzymes, which have been previously found to be active on glycerol $[25,29]$. HMF oxidation to DFF as the only product was recently observed with $M t$ GLOX; however this enzyme was unable to further oxidize DFF in the reaction [32]. Enzymes known to convert HMF to DFF include also AAO, alcohol oxidase, GAO, and HMFO [16, $18,19,33,34]$ and these enzymes showed higher yields of DFF compared to PciGLOX. However, the substrate specificity and catalytic efficiencies of PciGLOX2 and PciGLOX3 on DFF as a substrate $(K \mathrm{~m}=0.2 \mathrm{mM}$; $K c a t / K m=23,403 \quad \mathrm{~s}^{-1} \quad \mathrm{M}^{-1} \quad$ and $K \mathrm{~m}=0.2 \quad \mathrm{mM}$; $K c a t / K \mathrm{~m}=7267 \mathrm{~s}^{-1} \mathrm{M}^{-1}$, respectively) were significantly better than that of AAO from P. eryngii $(K \mathrm{~m}=3.3 \mathrm{mM}$; $\left.K c a t / K \mathrm{~m}=158 \mathrm{~s}^{-1} \mathrm{M}^{-1}\right)$ and HMFO $(K \mathrm{~m}=1.7 \mathrm{mM}$; $\left.K c a t / K m=940 \quad \mathrm{~s}^{-1} \quad \mathrm{M}^{-1}\right) \quad[18,19] . \quad P c i G L O X 2$ and PciGLOX3 were also more efficient than PciGLOX1 in oxidizing DFF which explains the presence of constant concentrations of DFF with PciGLOX1. On the other hand, in the cases of PciGLOX2 and PciGLOX3, it is more likely that DFF was produced and consumed very fast in the reaction.

On the contrary, the major reaction product, HMFCA was very weakly oxidized by PciGLOX. In addition, although the three enzymes and especially PciGLOX2 and PciGLOX3 were able to oxidize HMF, higher concentrations of FFCA and FDCA were obtained when the enzymes were reacted with DFF and FFCA as substrates, respectively.

In the reactions of PciGLOX on HMF, very little DFF is produced compared to the "dead-end product" HMFCA which might be strongly altering the stability of the enzymes at early stages of the reaction preventing further oxidation steps. In addition, the obtained results suggest that similarly to AAO, HMFO and chloroperoxidase [18, 19, 34], PciGLOX enzymes produce FFCA mainly via the oxidation of DFF (Fig. 1), which is a minor product in the oxidation of HMF by PciGLOX. However, PciGLOX are more specific and catalytically efficient than these enzymes in oxidizing DFF. For these reasons a cascade reaction, where UmaAAO was used to oxidize HMF followed by the addition of PciGLOX, was tested. AAO was previously used in tandem reactions with an unspecific oxidase for the oxidation of HMF $[18,33]$. Similarly to the AAOs from Pleurotus eryngii and P. ostreatus, UmaAAO generates FFCA via the oxidation of HMF to DFF [18, 
33]. UmaAAO was also found as efficient as P. eryngii AAO in oxidizing HMF leading to full conversion after $2 \mathrm{~h}$ of reaction. In contrary to $P$. eryngii AAO, UmaAAO seems less efficient in converting DFF to FFCA in the reaction. However, the used concentration of UmaAAO in this study is significantly lower and a kinetic study is needed to determine the efficiency.

In the current PciGLOX tandem reaction, the obtained yields of FDCA were lower compared to the ones obtained in the cascade reactions with UPO $[18,33]$. A limiting step in the reaction of PciGLOX seems to be the conversion of FFCA to FDCA and this was observed when FFCA was used as initial substrate. This effect is most possibly due to exogenous factors affecting the reaction since the enzymes exhibit relatively high specificity and catalytic efficiency towards FFCA. A probable factor could be the inhibition of the enzymes by the substrate and/or the product of the reaction. A second possible factor affecting this reaction is the accumulation of $\mathrm{H}_{2} \mathrm{O}_{2}$ throughout the first oxidation steps inhibiting the progress of the reaction in the FFCA oxidation stage. The sensitivity of PciGLOX enzymes in the presence of $\mathrm{H}_{2} \mathrm{O}_{2}$ supports this hypothesis. It is also interesting that this effect was previously reported for $P$. ostreatus AAO where the sensitivity of FFCA oxidation reaction to $\mathrm{H}_{2} \mathrm{O}_{2}$ was 300-times higher than that of the initial reaction [33].

\section{Conclusion}

The potential of PciGLOX for the production of valuable furan derivatives from HMF was investigated in this work. The three GLOX belonging to the same organism and sharing high sequence similarity of $84-89 \%$, showed differences in their catalytic properties and product patterns on the same substrates. Although known for their activity on aldehydes, these proteins were also able to act on the alcohol group of the substrate. Previously, this activity has been explained by the hypothesis that enzymes such as HMFO for example recognizes the hydrated form of the aldehyde in the reaction which explains their activity on DFF that rapidly forms hydrate in buffer pH 5-8 [19]. When the substrate has a carboxylic acid group in addition to the aldehyde group such as in the case of FFCA, the formation of hydrate is highly unfavorable and this explain the low activity of HMFO on FFCA [19, 35]. However, PciGLOX were active on FFCA and were found to efficiently oxidize the aldehyde group of HMF. HMF was previously reported not to form gemdiol under conditions similar to the ones used in this work [18]. This shows that PciGLOX are able to recognize and oxidize both aldehyde and, in certain cases, alcohol groups. HMFCA remains the major product of the reaction preventing the production of FDCA. However, the specificity of PciGLOX towards producing HMFCA itself can be considered of high biotechnological significance. The addition of catalase, to remove the influence of selfinhibition through the production of $\mathrm{H}_{2} \mathrm{O}_{2}$, improved reaction yields, while the addition of an AAO prior to the addition of PciGLOX shifted the reaction pathway through DFF and towards the production of FDCA, the desired precursor for bioplastic synthesis.

\section{Materials and methods \\ Chemicals and enzymes}

All chemicals were of analytical grade. HMF, DFF, HMFCA, FFCA, FDCA, 2,2'-azino-bis(3-ethylbenzothiazoline-6-sulphonic acid (ABTS) and glyoxylic acid, together with the enzymes HRP and catalase were purchased from Sigma Aldrich (Lyon, France). The glyoxal oxidases from Pycnoporus cinnabarinus, PciGLOX1 and PciGLOX2, were heterologously produced in Aspergillus niger as described previously [25]. The same protocol was used to produce the third isoform, PciGLOX3, and is reported here for the first time. The aryl alcohol oxidase (AAO) from Ustilago maydis (UmaAAO) was produced as previously reported in our laboratory [36]. The sequences of PciGLOX1, PciGLOX2 and PciGLOX3 are available in GenBank under accession numbers KU215437, KU215438 and MK268804, respectively.

\section{Enzyme activity assay}

The activity of the three PciGLOX enzymes was assayed in a coupled reaction with HRP following the protocol previously described [25]. When purified, GLOX enzymes are inactive and their oxidative activation was found to be possible in the presence of lignin peroxidase or HRP, or by the addition of strong oxidants such as molybdicyanide $\left(\mathrm{K}_{3} \mathrm{Mo}(\mathrm{CN})_{8}\right)$, hexachloroiridate $\left(\mathrm{Na}_{2} \mathrm{IrCl}_{6}\right)$, or $\mathrm{Mn}^{3+}$ EDTA [24, 37]. HRP was used in this study since it is readily obtained commercially, highly stable under the conditions used, and does not act on any of the substrates under investigation for oxidation by GLOX. The reaction mixture consisted of $50 \mathrm{mM}$ sodium tartrate buffer ( $\mathrm{pH} 6$ ) containing HRP (8 Units), $0.1 \mathrm{mM}$ ABTS, PciGLOX $(1 \mu \mathrm{g})$ and GLOX substrate at varying concentrations depending on the reaction in $1 \mathrm{~mL}$ final volume. The lag period was eliminated by adding $5 \mu \mathrm{M}$ $\mathrm{H}_{2} \mathrm{O}_{2}$. The reaction was initiated by the addition of the GLOX substrate and the oxidation of ABTS was followed at $436 \mathrm{~nm}$ for $1.5 \mathrm{~min}$. The standard assay was performed at $30^{\circ} \mathrm{C}$. All assays were performed in triplicate.

\section{PciGLOX3 characterization}

The substrate specificity of PciGLOX3 on $10 \mathrm{mM}$ of previously tested molecules (Table 1) with PciGLOX1 and PciGLOX2 was investigated following the activity test described above. The same standard assay was used to 
determine the kinetic constants for PciGLOX3 on methylglyoxal (0.02 to $5 \mathrm{mM}$ ), glyoxal (0.1 to $7 \mathrm{mM}$ ), glyoxylic acid (0.1 to $10 \mathrm{mM})$, and glycerol $(0.3$ to $80 \mathrm{mM})$ as substrates. Lineweaver-Burk plots, obtained using the GraFit (version 4) program [38], were used to calculate the kinetic parameters.

The three PciGLOX sequences were aligned using the ClustalW program within the MegAlign module (version 11.0.0) of DNAStar software (Madison, WI).

\section{Enzyme stability}

The three PciGLOX were incubated at $30{ }^{\circ} \mathrm{C}$ and $800 \mathrm{rpm}$ agitation for $48 \mathrm{~h}$ in $50 \mathrm{mM}$ sodium tartrate buffer $\mathrm{pH}$ 6. Samples were taken after 2, 4, 24 and $48 \mathrm{~h}$ and the residual activity was measured using glyoxylic acid as substrate and calculated as a percentage of the activity at time zero. The same experiment was also performed in the presence of $3 \mathrm{mM}$ HMF or HMFCA to determine the stability of the enzymes in the presence of these molecules. The stability of HRP was also assessed under the same conditions. All measurements were performed in triplicates.

\section{Kinetic studies}

The coupled reaction with HRP and ABTS under standard conditions was used to determine the steady-state kinetic parameters for PciGLOX oxidation of HMF (0.3$50 \mathrm{mM})$, DFF (0.01-2 mM), HMFCA (0.1-3 $\mathrm{mM})$ and FFCA $(0.2-5 \mathrm{mM})$. Kinetic parameters were obtained by fitting the data to the Michaelis-Menten equation using R statistical software (R Core Team, Vienna Austria).

\section{HPLC analysis of reaction products}

All oxidation reactions were performed at $30{ }^{\circ} \mathrm{C}$ under agitation at $800 \mathrm{rpm}$ in Eppendorf ThermoMixer tubes (Eppendorf, Montesson, France) over $24 \mathrm{~h}$ period in $100 \mathrm{mM}$ tartrate buffer, $\mathrm{pH}$ 6. To follow the reaction of the three PciGLOX isoenzymes on HMF, DFF, HMFCA and FFCA over time, reaction mixtures containing PciGLOX $(20 \mu \mathrm{g})$, HRP (8 Units), ABTS $(0.1 \mathrm{mM})$ and the substrate $(3 \mathrm{mM})$ were prepared. Samples were taken after $0,0.5,1,1.5,2,3,4,5,6,8$ and $24 \mathrm{~h}$ and analyzed. Reactions containing the same constituents except PciGLOX were followed for the same period of time and used as controls. All measurements were performed in duplicates.

Reaction mixtures were separated on Aminex HPX$87 \mathrm{H}$ column $(300 \times 7.8 \mathrm{~mm})($ BioRad $)$ at $45{ }^{\circ} \mathrm{C}$, with $2.5 \mathrm{mM}$ sulfuric acid as the mobile phase with a flow rate of $0.6 \mathrm{~mL} / \mathrm{min}$. Eluted compounds were detected using a diode array detector at $280 \mathrm{~nm}$. The reactions were stopped by incubating the mixture at $90{ }^{\circ} \mathrm{C}$ for $10 \mathrm{~min}$ and centrifuging at $15,000 \times g$ for $15 \mathrm{~min}$. The samples were then filtered using $0.45 \mu \mathrm{m}$ polyvinylidene difluoride syringe filters (Restek, Lisses, France) before injection in the column. Peak areas from the obtained chromatograms were converted to molar concentration using calibration curves of pure substrates and products standards.

The percentage conversion of the used substrate was determined according to the following equation:

$$
\begin{aligned}
\% \text { Conversion }= & \left(1-\frac{\text { Concentration of substrate }}{\text { Initial concentration of substrate }}\right) \\
& \times 100
\end{aligned}
$$

The percentage yield of the reaction products was determined according to the following equation:

$$
\% \text { Yield }=\left(\frac{\text { Concentration of product }}{\text { Initial concentration of substrate }}\right) \times 100
$$

\section{Effect of $\mathrm{H}_{2} \mathrm{O}_{2}$ on $\mathrm{HMF}$ oxidation}

The stability of the three PciGLOX isoenzymes in the presence of $\mathrm{H}_{2} \mathrm{O}_{2}$ was assessed by measuring the residual activity of the enzymes after pre-incubation with different concentrations of $\mathrm{H}_{2} \mathrm{O}_{2}$ over $24 \mathrm{~h}$. The $\mathrm{H}_{2} \mathrm{O}_{2}$ was removed before adding the enzyme to the reaction mixture by washing the samples with buffer in Amicon ultrafiltration unit with a 10-kDa-molecular-mass-cut-off membrane (Merck Millipore). All measurements were performed in duplicate.

To determine the effect of hydrogen peroxide on the oxidation of HMF and its derivatives by PciGLOX, the standard reaction was performed in the presence of $10 \mu \mathrm{g}$ catalase (2000-5000 Units/mg protein). The reaction was followed over time as described above. A control reaction containing all the components except PciGLOX was analyzed to determine the effect of catalase on HMF oxidation.

\section{PciGLOX and UmaAAO cascade reactions}

The oxidation of HMF by UmaAAO in the presence and absence of $10 \mu \mathrm{g}$ catalase was followed. The reaction mixture contained UmaAAO $(20 \mu \mathrm{g})$ and HMF $(3 \mathrm{mM})$ in $100 \mathrm{mM}$ tartrate buffer, $\mathrm{pH} 6$. Samples were taken after 0 , $0.5,1,1.5,2,3,4,5,6,8$ and $24 \mathrm{~h}$ and analyzed on HPLC. All measurements were performed in duplicates.

UmaAAO was then used in a cascade reaction with PciGLOX3 for the oxidation of HMF and its derivatives. The reaction was performed by reacting UmaAAO with HMF for 2 or $24 \mathrm{~h}$ before adding PciGLOX3. Following the addition of PciGLOX3, the samples were further incubated for 4 or $24 \mathrm{~h}$ and then analyzed. The reactions 
were again performed in the presence and absence of catalase.

\section{Statistical analysis}

The statistical analyses of data on the effect of catalase on the activity of PciGLOX on HMF and the effect of PciGLOX3 on the production of FDCA in the cascade reaction with UmaAAO were performed by the nonparametric Kruskal-Wallis test (Kruskal \& Wallis, 1952; $\mathrm{p}<0.05$ ). The analysis was followed by post hoc Dunn pairwise comparison test (Dunn 1964) when differences were significant.

\section{Additional files}

Additional file 1. Stability of HRP under the reaction conditions. Residual activity of HRP on ABTS after incubation for different time periods (0-24 h) in tartrate buffer $\mathrm{pH} 6$ at $30^{\circ} \mathrm{C}$ and $800 \mathrm{rpm}$ (back) and in the presence of 3 mM HMF (blue) or HMFCA (green).

Additional file 2. HPLC chromatogram of the reactions of PCiGLOX and UmaAAO on HMF. HPLC chromatogram of the reactions of (a) PCiGLOX1 (red), PciGLOX2 (green) and PciGLOX3 (pink) enzymes on HMF after $24 \mathrm{~h}$ of incubation compared to the control (blue) and (b) UmaAAO on HMF at t (blue) and after $1 \mathrm{~h}$ (red), $2 \mathrm{~h}$ (green), $4 \mathrm{~h}$ (pink) and $24 \mathrm{~h}$ (grey) of reaction.

\section{Abbreviations}

HMF: 5-hydroxymethylfurfural; FDCA: 2,5-furandicarboxylic acid; DFF: diformylfuran; HMFCA: 5-hydroxymethyl-2-furancarboxylic acid; GAO: galactose oxidase; AAO: aryl alcohol oxidase; HMFO: HMF oxidase; GLOX: glyoxal oxidase; FFCA: 5-formyl-2-furan carboxylic acid; ABTS: 2,2'-azino-bis(3-ethylbenzothiazoline-6-sulphonic acid; XO: xanthine oxidase; HRP: horseradish peroxidase.

\section{Authors' contributions}

$M D, C B F$ and ER designed the experiments. MD and SW performed the production and biochemical characterization of PCiGLOX3. MD and BY performed the reactions and HMF and the HPLC analysis. MD, EB, CBF and ER analyzed and interpreted the data and results. MD was the major contributor in writing the manuscript. CBF, EB, FD and ER provided critical feedback and helped in writing the manuscript. All authors read and approved the final manuscript.

\section{Author details}

1 INRA, UMR1163 Biodiversité et Biotechnologie Fongiques (BBF), Aix Marseille Université, 13009 Marseille, France. ${ }^{2}$ CNRS, Centrale Marseille, Aix-Marseille Université, M2P2, Marseille, France.

\section{Acknowledgements}

Not applicable.

\section{Competing interests}

The authors declare that they have no competing interests.

\section{Availability of data and materials}

The datasets used and/or analyzed during the current study are available from the corresponding author on reasonable request.

\section{Consent for publication \\ Not applicable.}

Ethics approval and consent to participate Not applicable.

\section{Funding}

This project has received funding from the Bio Based Industries Joint Undertaking under the European Union's Horizon 2020 research and innovation program under Grant agreement No. 720303 (project Zelcor), and the FP7 program within the INDOX project (KBBE-2013-7-613549). We would also gratefully acknowledge the research federation ECCOREV (ECosystème COntinentaux et Risques EnVironnementaux) for providing a Masters grant to BY, and to the French Embassy in Thailand for a Junior Research Fellowship for SW.

\section{Publisher's Note}

Springer Nature remains neutral with regard to jurisdictional claims in published maps and institutional affiliations.

Received: 17 December 2018 Accepted: 15 March 2019

Published online: 01 April 2019

\section{References}

1. Röper H. Renewable raw materials in Europe-industrial utilisation of starch and sugar. Starch-Stärke. 2002;54(3-4):89-99.

2. Li H, Yang S, Riisager A, Pandey A, Sangwan RS, Saravanamurugan S, et al. Zeolite and zeotype-catalysed transformations of biofuranic compounds. Green Chem. 2016;18(21):5701-35.

3. Chheda JN, Román-leshkov Y, Dumesic JA. Production of 5-hydroxymethylfurfural and furfural by dehydration of biomass-derived mono- and poly-saccharides. Green Chem. 2007;9(4):342-50.

4. Conner AH, Bhuiyan MSH. Wood: adhesives. Elsevier, 2017. ISBN: 978-012-803581-8. https://doi.org/10.1016/B978-0-12-803581-8.01932-9.

5. Gandini A, Silvestre AJD, Neto CP, Sousa AF, Gomes M. The furan counterpart of poly (ethylene terephthalate): an alternative material based on renewable resources. J Polym Sci A. 2009;47(1):295-8.

6. Rosatella AA, Simeonov SP, Frade RFM, Afonso CAM. 5-Hydroxymethylfurfural (HMF) as a building block platform: biological properties, synthesis and synthetic applications. Green Chem. 2011;13(4):754-93.

7. Hopkins KT, Wilson WD, Bender BC, McCurdy DR, Hall JE, Tidwell RR, et al. Extended aromatic furan mmidino derivatives as anti-Pneumocystis carinii agents. J Med Chem. 1998;41(20):3872-8.

8. Del Poeta M, Schell WA, Dykstra CC, Jones S, Tidwell RR, Czarny A, et al. Structure-in vitro activity relationships of pentamidine analogues and dication-substituted bis-benzimidazoles as new antifungal agents. Antimicrob Agents Chemother. 1998;42(10):2495-502.

9. Benahmed-Gasmi A, Frère P, Jubault M, Gorgues A, Cousseau J, Garrigues B. 2,5-Bis (1,4-dithiafulven-6-yl) substituted furans, thiophenes and $\mathrm{N}$-methyl pyrroles as precursors for organic metals. Synth Met. 1993:56:1751-5.

10. Amarasekara AS, Green D, Williams LD. Renewable resources based polymers: synthesis and characterization of 2,5-diformylfuran-urea resin. Eur Polym J. 2009;45(2):595-8.

11. Hirai H. Oligomers from hydroxymethylfurancarboxylic acid. J Macromol Sci A Chem. 1984;21(8-9):1165-79.

12. Braisted AC, Oslob JD, Delano WL, Hyde J, McDowell RS, Waal N, et al. Discovery of a potent small molecule IL-2 inhibitor through fragment assembly. J Am Chem Soc. 2003;125(13):3714-5.

13. Munekata M, Tamura G. Antitumor activity of 5-hydroxy-methyl-2-furoic acid. Agric Biol Chem. 1981;45(9):2149-50.

14. Werpy T, Petersen G, Aden A, Bozell J, Holladay J, White J, et al. Top value added chemicals from biomass. Volume 1 -Results of screening for potential candidates from sugars and synthesis gas. US; 2004. DTIC Document.

15. Zhang Z, Deng K. Recent advances in the catalytic synthesis of 2,5-furandicarboxylic acid and Its derivatives. ACS Catal. 2015;5(11):6529-44.

16. Qin YZ, Li YM, Zong MH, Wu H, Li N. Enzyme-catalyzed selective oxidation of 5-hydroxymethylfurfural (HMF) and separation of HMF and 2,5-diformylfuran using deep eutectic solvents. Green Chem. 2015;17(7):3718-22. 
17. Zhang Z, Liu B, Lv K, Sun J, Deng K. Aerobic oxidation of biomass derived 5-hydroxymethylfurfural into 5-hydroxymethyl-2-furancarboxylic acid catalyzed by a montmorillonite K-10 clay immobilized molybdenum acetylacetonate complex. Green Chem. 2014;16(5):2762-70.

18. Carro J, Ferreira P, Rodriguez L, Prieto A, Serrano A, Balcells B, et al. 5-Hydroxymethylfurfural conversion by fungal aryl-alcohol oxidase and unspecific peroxygenase. FEBS J. 2015;282(16):3218-29.

19. Dijkman WP, Groothuis DE, Fraaije MW. Enzyme-catalyzed oxidation of 5-hydroxymethylfurfural to furan-2,5-dicarboxylic acid. Angew Chem Int Ed. 2014;53(25):6515-8.

20. Dijkman WP, Binda C, Fraaije MW, Mattevi A. Structure-based enzyme tailoring of 5-hydroxymethylfurfural oxidase. ACS Catal. 2015;5(3):1833-9.

21. Whittaker MM, Kersten PJ, Cullen D, Whittaker JW. Identification of catalytic residues in glyoxal oxidase by targeted mutagenesis. J Biol Chem. 1999;274(51):36226-32.

22. Cantarel BL, Coutinho PM, Rancurel C, Bernard T, Lombard V, Henrissat B. The Carbohydrate-Active EnZymes database (CAZy): an expert resource for glycogenomics. Nucleic Acids Res. 2009;37(database issue):D233-8.

23. Levasseur A, Drula E, Lombard V, Coutinho P, Henrissat B. Expansion of the enzymatic repertoire of the CAZy database to integrate auxiliary redox enzymes. Biotechnol Biofuels. 2013;6(1):41.

24. Kersten PJ. Glyoxal oxidase of Phanerochaete chrysosporium: its charac terization and activation by lignin peroxidase. Proc Natl Acad Sci USA. 1990:87(8):2936-40.

25. Daou M, Piumi F, Cullen D, Record E, Faulds CB. Heterologous production and characterization of two glyoxal oxidases from Pycnoporus cinnabarinus. Appl Environ Microbiol. 2016;82(16):4867-75.

26. Kersten PJ, Kirk TK. Involvement of a new enzyme, glyoxal oxidase, in extracellular $\mathrm{H}_{2} \mathrm{O}_{2}$ production by Phanerochaete chrysosporium. J Bacteriol. 1987;169(5):2195-201.

27. Martinez D, Larrondo LF, Putnam N, Gelpke MDS, Huang K, Chapman J, et al. Genome sequence of the lignocellulose degrading fungus Phanerochaete chrysosporium strain RP78. Nat Biotechnol. 2004;22:695.
28. Levasseur A, Lomascolo A, Chabrol O, Ruiz-Dueñas FJ, Boukhris-Uzan E, Piumi F, et al. The genome of the white-rot fungus Pycnoporus cinnabarinus: a basidiomycete model with a versatile arsenal for lignocellulosic biomass breakdown. BMC Genom. 2014;15(1):486.

29. Roncal T, Munoz C, Lorenzo L, Maestro B, Diaz De Guerenu MDM. Two-step oxidation of glycerol to glyceric acid catalyzed by the Phanerochaete chrysosporium glyoxal oxidase. Enzyme Microb Technol. 2012;50(2):143-50.

30. Kurek B, Kersten PJ. Physiological regulation of glyoxal oxidase from Phanerochaete chrysosporium by peroxidase systems. Enzyme Microb Technol. 1995;17(8):751-6.

31. Hernandez K, Berenguer-Murcia A, Rodrigues CR, Fernandez-Lafuente R. Hydrogen peroxide in biocatalysis: a dangerous liaison. Curr Org Chem. 2012;16(22):2652-72.

32. Kadowaki AM, Godoy OM, Kumagai SP, Costa-Filho JA, Mort A, Prade AR, et al. Characterization of a new glyoxal oxidase from the thermophilic fungus Myceliophthora thermophila M77: hydrogen peroxide production retained in 5-hydroxymethylfurfural oxidation. Catalysts. 2018;8(10):476.

33. Karich A, Kleeberg SB, Ullrich R, Hofrichter M. Enzymatic preparation of 2,5-furandicarboxylic acid (FDCA) — a substitute of terephthalic acid-by the joined action of three fungal enzymes. Microorganisms. 2018;6(1):5.

34. Hanke PD, Archer Daniels Midland Company. Enzymatic oxidation of hydroxymethylfurfural; 2012. US Patent 8,183,020.

35. McKenna SM, Leimkühler S, Herter S, Turner NJ, Carnell AJ. Enzyme cascade reactions: synthesis of furandicarboxylic acid (FDCA) and carboxylic acids using oxidases in tandem. Green Chem. 2015;17(6):3271-5.

36. Couturier M, Mathieu Y, Li A, Navarro D, Drula E, Haon M, et al. Characterization of a new aryl-alcohol oxidase secreted by the phytopathogenic fungus Ustilago maydis. Appl Microbiol Biotechnol. 2016;100(2):697-706.

37. Whittaker MM, Kersten PJ, Nakamura N, Sanders-Loehr J, Schweizer ES, Whittaker JW. Glyoxal oxidase from Phanerochaete chrysosporium is a new radical-copper oxidase. J Biol Chem. 1996;271(2):681-7.

38. Leatherbarrow RJ. GraFit version 4.0. Staines: Erithacus Software Ltd; 1998.
Ready to submit your research? Choose BMC and benefit from:

- fast, convenient online submission

- thorough peer review by experienced researchers in your field

- rapid publication on acceptance

- support for research data, including large and complex data types

- gold Open Access which fosters wider collaboration and increased citations

- maximum visibility for your research: over $100 \mathrm{M}$ website views per year

At BMC, research is always in progress.

Learn more biomedcentral.com/submissions 